\title{
MONSEÑOR PABLO CABRERA: EL "DEBER SER NACIONAL" Y EL "DEBER SER CIUDADANO" EN SUS SERMONES
}

\author{
Monsignor Pablo Cabrera: The "national's must be" \\ and the "citizen's must be" in his sermons
}

\section{Denise Reyna Berrotarán*}

\section{Resumen}

Monseñor Pablo Cabrera fue un sacerdote-historiador que tuvo relevancia en la historia de Córdoba a fines del siglo XIX y principios del XX. Sus distintas facetas fueron otorgándole reconocimiento en distintos espacios de la cultura cordobesa, entre las que podemos mencionar su rol como historiador, etnógrafo, etnólogo, coleccionista de documentos, y orador sagrado, entre otras.

En este trabajo nos concentraremos en su faceta de orador sagrado. La oratoria sagrada tuvo como función difundir, desde una cultura de oralidad, el mensaje que la Iglesia necesitaba hacer llegar a la sociedad a través de dirigentes reconocidos. Sus mensajes intentaban generar consciencia sobre distintas temáticas de preocupación general. Estos direccionaban hacia el accionar correcto, dentro de un cuerpo de valores morales. En este trabajo analizaremos los sermones cívicos de Cabrera y cuáles eran los mensajes que intentó transmitir a la sociedad cordobesa y/o argentina. Caracterizaremos las formas de preparación de sus piezas oratorias y nos detendremos en el análisis de dos sermones cívicos de 1902: un Te Deum para los Pactos de Mayo; y una pieza oratoria para la fiesta del 25 de mayo.

$<$ Historia de Córdoba $><$ Oratoria sagrada $><$ Deber ser nacional $><$ Monseñor Pablo Cabrera $>$

\begin{abstract}
Monsignor Pablo Cabrera was a priest-historian who had relevance in the history of Cordoba in the late nineteenth and early twentieth centuries. His various facets granted him recognition in different areas of the culture of Cordoba, such as his role as a historian, ethnographer, ethnologist, collector of documents, and sacred speaker among others.

In this paper, I will focus on his role as a sacred orator. The function of the sacred oratory was to disseminate the message that the Church needed to reach society through recognized leaders, from an oral culture. The messages of Cabrera tried to generate awareness on various issues of general concern. These messages shaped the path to the correct action within a body of moral values. In this regard, I will also analyze the civic sermons of Cabrera and the messages he tried to convey to the society of Cordoba and Argentina. In addition, I will characterize the ways of preparing his oratorical pieces, focusing on the analysis of two civic sermons of 1902: a Te Deum for the Pacts of May, and a sermon for the celebration of May 25.
\end{abstract}

$<$ History of Cordoba $><$ Sacred oratory $><$ National's must be $><$ Monsignor Pablo Cabrera $>$

Recibido: 10/05/2016 // Aceptado: 16/09/2016

* Prof. de Historia. Facultad de Filosofía y Humanidades de la Universidad Nacional de Córdoba, Centro de Investigaciones de la misma Facultad (CIFFyH) y CEA-UNC. denisereynab@gmail.com 


\section{Introducción}

La cátedra sagrada ha tenido a lo largo de la historia un lugar central en la difusión de los distintos mensajes que la Iglesia buscaba hacer llegar a sus seguidores. Los oradores no sólo se centraban en la explicación de relatos bíblicos o cuestiones puramente religiosas, sino que muchas veces eran formas de difundir los "buenos comportamientos" ante distintos contextos que estaba viviendo la sociedad. Esto nos lleva a pensar que los oradores sagrados eran el resultado de un contexto y que sus alocuciones eran interpelados por este. En este sentido coincidimos con Verónica Zaragoza, quien, citando a Carlos Herrejón Peredo, considera al sermón como una manifestación cultural propia en tanto fenómeno histórico y género literario peculiar (Zaragoza, 2008: 20).

Desde sus diversos contextos, los sermones transmitían un mensaje que enseñaba cómo ser un "buen cristiano" -lo cual muchas veces se igualó a ser "buen ciudadano"y que les mostraba el camino adecuado ante los distintos acontecimientos cotidianos. Estas cátedras sagradas traspasaban los niveles de lo espiritual y se manifestaban, entrelíneas, ante distintas realidades políticas de las que los creyentes estaban siendo parte. "Los sermones se convirtieron en la guía del 'buen vivir del cristiano', debido a que en ellos se daban las pautas del comportamiento y de buena conducta" (Sánchez Gaete, 2008: 53).

A principios del Siglo XX en Argentina, en un proceso de cambios poblacionales, culturales e identitarios notorios, la oratoria sagrada se convirtió en una forma de contención y "unión” para los católicos. Este fue uno de los espacios que la Iglesia utilizó para marcar las directrices de un buen ciudadano cristiano y para formar una identidad nacional en consonancia con un cristiano "obediente".

A su vez, en este mundo de la cátedra sagrada existieron sermones que se realizaban para la celebración de eventos patrios y efemérides. Los eventos cívicos se complementaban con celebraciones litúrgicas en las que oradores distinguidos componían sermones, homilías, y otras piezas retóricas. Estos movimientos cívicos eran aprobados y concebidos como obra de Dios (Martínez de Sánchez, 2010: 10). De esta manera, los conceptos de libertad, patria, independencia, ciudadano, se hicieron presentes en los sermones patrios como forma de explicar la nación y justificar la relevancia de dichos acontecimientos.

Monseñor Pablo Cabrera (1857-1936) fue un sacerdote-historiador que tuvo gran influencia en los estudios sobre el pasado colonial en Argentina -sobre todo de la región de Córdoba- y fue considerado en su época un intelectual de relevancia. $\mathrm{Su}$ filiación con la Iglesia Católica -se ordena como presbítero en el Seminario Conciliar de Loreto de Córdoba en 1883- le dio a sus estudios un tinte reivindicativo religioso. Lo más llamativo podría decirse que fue su capacidad de conjugar su aspecto religioso con su participación en el espacio público, su reconocimiento a nivel nacional e incluso internacional y su estudio de lo local. Cabrera empieza a ser reconocido en el espacio público a partir de la cátedra sagrada, a fines del siglo XIX. Sin embargo, su carrera de 
orador sagrado concluyó a principios del siglo XX. Desde entonces y hasta su muerte, se dedicó a la investigación histórica.

El objetivo de este artículo, entonces, será realizar un encuadre de su rol como orador sagrado, para luego concentrarnos en dos sermones cívicos que dio en el año 1902. Uno fue un Te Deum ante los Pactos de Paz entre Chile y Argentina; el segundo sermón cívico, lo realizó en los festejos del 25 de Mayo. Analizaremos en estos sermones de qué manera intenta exponer, como él dice: "oidme generosos argentinos", las pautas para la nación y el deber ser como ciudadanos pertenecientes a una sociedad independiente y en progreso.

La razón de la elección de estos dos sermones radica en que el Cabrera orador sagrado de principios de siglo XX es más experimentado en la práctica discursiva y más incisivo en expresión de ciertas opiniones, cuestión que cuesta más verla en sus primeros sermones en la década de 1880. Esto facilitó el análisis del deber ser ciudadano y deber ser nacional.

\section{Monseñor Pablo Cabrera (1857- 1936): una breve biografía intelectual ${ }^{1}$}

Cabrera tuvo gran influencia en los estudios sobre el pasado colonial argentino, sobre todo en Córdoba del Tucumán, lo que lo llevó a ser considerado en su época un intelectual de relevancia. Su filiación con la Iglesia Católica le dio a sus estudios un tinte reivindicativo religioso que lo ubicó socialmente como el "disipador de la leyenda negra"2. Lo más llamativo fue su capacidad de conjugar su aspecto religioso con su participación en el espacio público, su reconocimiento a nivel nacional e, incluso internacional, y su estudio de lo local.

Cabrera empezó a ser reconocido en el espacio público a partir de la cátedra sagrada a fines del siglo XIX. Sin embargo, su carrera de orador sagrado concluyó a principios del siglo XX. Desde entonces y hasta su muerte, se dedicó a los estudios históricos. Esto le permitió convertirse en un intelectual de renombre y con los años fue formando un grupo de discípulos a su alrededor -afirma Enrique Martínez Paz en un elogio a su persona en $1936^{3}$-, que continuarían su obra desde lo temático, teórico y

\footnotetext{
1 Es menester destacar que este trabajo se enmarca en una investigación de mayor alcance sobre Pablo Cabrera titulada: Monseñor Pablo Cabrera: un sacerdote-historiador. Sus intervenciones sobre el pasado y el presente (1857-1936), en la que se analiza toda su trayectoria como sacerdote-historiador. Se investiga toda su biografía y las distintas etapas con sus características propias. El único autor que trabajó de manera integral integral, desde la disciplina histórica, sobre Cabrera hasta el momento fue Guillermo Furlong Cardiff (1945).

2 En 1928, la Universidad Nacional de Córdoba le otorgó a Cabrera el título de Doctor Honoris Causa. Este evento fue publicado en varios periódicos leídos por los grupos conservadores y católicos de Córdoba. En uno de ellos: La Tribuna, Córdoba, 23 de junio de 1928, ubicado en la página central del periódico, se titulaba el evento como "Disipar la 'Leyenda Negra' es gloria de Mons Cabrera. Se rindió un merecido homenaje al esclarecido historiador, que es honra del clero de Córdoba". Para profundizar este homenaje véase Reyna Berrotarán (2015).

3 Instituto de Estudios Americanistas (1937).
} 
conceptual, hasta lo metodológico en el Instituto de Estudios Americanistas, creado a su muerte como homenaje a su obra y a su legado documental y bibliográfico.

Cabrera se caracterizó por la diversidad de ámbitos en los que tuvo participación y que le valieron el reconocimiento como "sabio" -como ellos se autodenominaban- de la sociedad cordobesa y argentina. Su trayectoria puede periodizarse en varias etapas en las que fueron primando distintos ejes de pensamiento. Aquí nos toca centrarnos en la etapa de mayor cercanía al trabajo eclesial, en donde su rol como historiador no estaba todavía tan desarrollado. Su notoriedad residió, por entonces, en su trabajo en los distintos espacios en la Iglesia y en su oratoria sagrada.

Dentro de esta fueron sus sermones los que le otorgaron un reconocimiento como sacerdote del púlpito. Esta actividad perduró aproximadamente hasta los primeros años del siglo XX, donde abandonó la cátedra sagrada para dedicarse a los estudios históricos. Su carrera como orador sagrado fue muy destacada y lo llevó a consagrarse como tal en este Te Deum de los Pactos de Mayo. Sin embargo, esta actividad se vio interrumpida por problemas vocales, como le comentó a Nices-Lotus en una entrevista en 1933: "Mi propia decisión. Esa misión tan noble y tan grande había llegado a absorber mi tiempo completamente (...) Una faringitis me sirvió de pretexto, pero como Usted sabe todavía ahora puedo hacerme oír"4.

El concionador realizó sus estudios en el Seminario de Loreto de Córdoba entre 1870 y 1881. Como el Seminario se cerró ese año, Cabrera recién pudo ordenarse como presbítero dos años después en Mendoza. Sus sermones fueron ganando reconocimiento en Mendoza y luego en Córdoba. Su tarea como orador sagrado fue creciendo en tanto realizaba sermones en distintos lugares.

Para cuando Cabrera realizó el discurso del Te Deum de 1902 ya tenía reconocimiento en los círculos católicos cordobeses y en las jerarquías eclesiásticas. Su faceta religiosa va a desarrollarse en gran parte gracias a la cátedra sagrada. Además de esto, al momento de los Pactos de Mayo, el sacerdote-historiador venía de dar un conjunto de sermones que seguían una línea de pensamiento religioso que apelaba a la unidad hispanoamericana y al fervor del Papa León XIII, del que Cabrera era un seguidor y admirador. En estos también planteaba como la religión guiaba a la patria y de qué manera sólo a través de Dios se podría llegar a la unidad.

\section{Monseñor Pablo Cabrera, el orador sagrado}

Si nos detenemos en los listados de piezas oratorias de Cabrera, recopiladas por Furlong Cardiff (Furlong Cardiff, 1945: 194-217) podemos observar desde sermones, panegíricos, conferencias y variados tipos de discursos. En sus sermones, la mayoría hacen alusión a cuestiones religiosas o festejos del calendario litúrgico referentes a la Cuaresma, Pascua, y Navidad, celebraciones de santos y distintas advocaciones de la Virgen. También se encuentran sermones sobre eventos cívicos como los del 25 de

${ }^{4}$ Entrevista de Nice-Lotus (seudónimo de Luis Gorosito Heredia, presbítero salesiano y literato): El Pueblo, Bs. As., 16 de julio de 1933. 
Mayo, 9 de Julio y de la Jura de la Bandera, entre otros. Casi ninguno detalla el lugar en que se proclamaron, y pocos tienen su fecha.

De toda esta abundante documentación se ha podido acceder a muy poca. Mucha de la que pudo conocer Furlong o los allegados a Cabrera en su época, hoy está extraviada. Con seguridad los sermones que el sacerdote- historiador pronunció no están en la colección que hoy lleva su nombre y que reúne unas 300 piezas de oratoria sagrada de diferentes épocas.

Las opiniones que hemos podido leer sobre su oratoria en general se centran en su capacidad de expresión, la elocuencia y los conocimientos que detentaba de distintas temáticas. Rescatamos lo que refirió monseñor Gustavo J. Franceschi:

"Le vi por primera vez en la Catedral de Buenos Aires en agosto de 1902. (...) Pronunció en el Te Deum un discurso que me impresionó profundamente. Había yo escuchado ya, para aquel entonces, a los oradores sagrados de más relieve en la Argentina, y me interesaba en gran manera su técnica. La de Padre Cabrera me pareció sobresaliente: método en el plan de exposición numerosa y rotunda frase, vívida la imagen. (...) Cabrera me pareció uno de los hombres más elocuentes entre los que hasta aquella fecha había yo oído" (Franceschi, 1936).

A partir de la comparación entre algunos sermones, podemos ver que Cabrera los armaba apoyándose en sus conocimientos de distintas temáticas y, sobre todo, en la historia, para darle más robustez a sus afirmaciones. Cuadriello aduce que, muchas veces, la celebración litúrgica ofrecía un sermón alusivo sazonado por la erudición histórica y el uso emblemático de intrincadas figuras literarias (Cuadriello, 1995: 231).

A este respecto parecería que el uso del pasado para sus sermones sobre diversos temas del presente fue una herramienta de su oratoria cotidiana. Sus operaciones de memoria no sólo se verán en sus diversos sermones sino también en sus obras escritas sobre temas históricos.

Si comparamos los primeros sermones y sus últimos, se evidencia que la seguridad en sus argumentaciones va en aumento. Esto denota el aumento de confianza en su tarea de orador. En un sermón que estipulamos era cercano a 1880, expone las ideas afirmando muy tibiamente cuestiones y comportamientos morales. Se puede ver su constante cuidado de no exponer posicionamientos políticos. A medida que avanzan los años y la práctica concionatoria, Cabrera va ganando reconocimiento en algunos círculos de la sociedad cordobesa. Esto le brinda más comodidad para aseverar ciertas cuestiones que hacen al acontecer cotidiano.

En este sentido, el orador sagrado irá ganando este reconocimiento por sus acciones llevadas adelante en las Esclavas del Corazón de Jesús, con quienes trabajó hasta fines del siglo XIX y que favorecieron su emergencia como presbítero de renombre en Córdoba. A su vez, su viaje a Roma para las Bodas de Oro sacerdotales de León XIII, sus vínculos en el Ateneo con el futuro obispo de Córdoba, Zenón Bustos y Ferreyra 
(López, 2010), y el título de monseñor (1908), son pasos que le brindan reconocimiento como sacerdote que es modelo de hombre, ciudadano y cristiano.

Un recurso recurrente que utiliza Cabrera en sus sermones es el de imaginación explicativa. Con esto nos referimos a su capacidad de crear imágenes en los oyentes para explicitar alguna línea relevante del sermón. Nuevamente, la historia aparece como ejemplo regular. También algunos ejemplos extraídos de la Biblia y religiosos. De esta manera, este recurso sirve para atraer y comprometer a la audiencia y, de alguna manera, lograr una vinculación entre el orador y quienes lo escuchan, dando lugar a un compromiso participativo por parte de la audiencia.

La oratoria sagrada, en general, se basaba en la buena capacidad discursiva y de expresión del disertante $\mathrm{y}$, también, de sus cualidades morales y normas de comportamiento. El orador estaba habilitado para exponer sus ideas ya que su vida era un testimonio de los buenos comportamientos morales. De esta manera, el orador gana su lugar no sólo por su capacidad, presencia y facilidad de comunicación de las ideas, sino también por el buen ejemplo en el accionar cotidiano y su congruencia entre el “decir" y el "hacer" (Martínez de Sánchez, 2010).

Una característica de las distintas piezas de oratoria de Cabrera era que todas comienzan con alguna cita bíblica en latín. Estos extractos de la Biblia después resultarán significativos para el discurso que se leerá. No encontramos ninguna pieza oratoria que no comience con alguna cita bíblica en latín. Otra característica de las piezas de oratoria de Cabrera es la selección de binomios de conceptos que los va haciendo jugar en distintos contextos, apelando a distintos “deber ser". Deber ser nacional, deber ser ciudadano, entre otros. Estos binomios se reiteran con la intención de insistir y fijar en la audiencia cuestiones que envuelven a todo el sermón.

\section{El deber ser nacional: Los Pactos de Mayo de 1902}

Los Pactos de Mayo fueron la etapa final de la resolución de un conjunto de conflictos en las relaciones entre Chile y Argentina. Lacoste ubica el comienzo de este proceso en 1879 (Lacoste, 2002). Durante este período se dieron sucesivos tratados, protocolos y reuniones diplomáticas en busca de esclarecer los límites entre ambos países, siempre buscando evitar la guerra. Sin embargo, aquí había una segunda disputa que plantea Lacoste y tenía que ver con un proceso de consolidación como potencias de América del Sur por parte de Chile y Argentina que eran los países más desarrollados al momento. Esto hay que ponerlo en tensión, según el autor, con el contexto internacional de Paz Armada, y la consecuente carrera armamentística que trajo aparejada, que afectó no solo a países europeos sino también, como demuestra el autor, a Argentina y Chile que se estaban preparando para una posible guerra.

Ante esto, los Pactos de Mayo no sólo resolvieron algunas cuestiones limítrofes, sino también tuvieron como otra cláusula importante el desarme naval de ambos países, dando comienzo a un período de paz; a diferencia de lo que ocurrió en Europa. 
Los Pactos de Mayo hacen referencia a tres protocolos que firmó el presidente chileno Germán Riesco Errázuriz con el argentino Julio Argentino Roca, el 28 de mayo de 1902 en Chile: el Tratado General de Arbitraje se encargó de establecer los límites territoriales entre ambos países; el Convenio de Limitación de Armamentos Navales apeló al desarme naval de ambos países promoviendo soluciones diplomáticas de futuros conflictos; y un Protocolo Adicional planteaba que se elegía como árbitro para emitir un fallo respecto de las cuestiones limítrofes a "Su Majestad Británica".

El Te Deum es una celebración de acción de gracias que generalmente se realiza para conmemorar algún evento beneficioso como una canonización, fecha patria, ordenación de presbíteros, entre otros. En este caso, este sermón responde a un evento cívico muy importante y era una de las formas de celebrar la paz lograda. El Te Deum permitió reforzar hechos políticos a través de rituales religiosos basados en las costumbres de nuestro país. "La liturgia del Te Deum así, aplicada en la celebración del sistema de poder terrenal, lograba canalizar en el imaginario colectivo la asociación de dicha cima celestial con la gloria de sus gobernantes. El triunfo ritual de la fe apoyaba simbólicamente el triunfo del poder político" (Valenzuela Márquez, 2001: 183).

\subsection{Análisis del Sermón dado en el Te Deum}

El Tedeum de los Pactos de Mayo se realizó el 24 de agosto de 1902 con motivo de la venida de una delegación chilena a firmar los pactos realizados en mayo del mismo año (Furlong Cardiff, 1945: 29). Se realizó en la Catedral de Buenos Aires ante diversas autoridades: "Exmo. Sr. Presidente de la República, Exmo. Sr Internuncio Apostólico y Ilmo. y Rmo. Sr Arzobispo" (Cabrera 1902a: 1) refiriéndose a Julio Argentino Roca, monseñor Antonio Sabatucci y monseñor Mariano A. Espinosa, respectivamente.

El sermón fue titulado por Cabrera como "Paz y Fraternidad". Con ese título se publicó luego en muchos periódicos del interior y bonaerenses (Furlong Cardiff, 1945: 119). Más tarde se decidió publicar un folleto en Córdoba, por parte de la Tipográfica La Industrial. Este es el documento que ha llegado a nuestras manos ${ }^{5}$. Hay varias cuestiones que emergen a partir del análisis del mismo.

A lo largo del discurso, el orador sagrado va a delinear las razones del título de su disertación, explicitará qué entiende por la Paz y la Fraternidad. En ambos casos, la historia será su herramienta básica para reivindicar estos conceptos y para justificar el éxito de la Iglesia y del poder político en estos hechos del momento. El orador sagrado alude reiteradamente a distintos momentos históricos, a distintos períodos para legitimar sus afirmaciones. Aunque todavía no estamos ante la presencia del Cabrera historiador en su máxima expresión, se puede visualizar cómo hace uso reiterado de la misma para legitimar a la Iglesia Católica y el poder político. A través de su expresión de los conceptos de "Paz" y "Fraternidad" podremos desentrañar esto.

La Paz y la Fraternidad son la causa y la consecuencia de los Pactos de Mayo y, a su vez, todo esto es posible gracias a la "acción providencial de Dios". Durante el

${ }^{5}$ El sermón fue consultado en el Archivo del Arzobispado de Córdoba. 
discurso se reitera el rol de la providencia divina como ejecutora de todos los éxitos acontecidos y de la religión católica como la única capaz de lograr la paz y la fraternidad entre pueblos hermanos. Mientras las naciones puedan ubicarse bajo la egida de la religión, para Cabrera será posible la Paz. Esto es lo que lograron Argentina y Chile.

\subsection{Concepto de "Fraternidad"}

"La fraternidad es más fuerte que la guerra" (Cabrera, 1902a: 03): con esa frase desarrolla las razones del triunfo de un abrazo fraternal -guiado por la providencia divina- entre ambos países. Para valerse de ello, reconstruye la historia de la relaciones entre Argentina y Chile, naciones que han creado un vínculo de amistad histórico que las lleva a buscar la fraternidad. Este puede retrotraerse a la generosidad de los chilenos a abrir las puertas de manera hospitalaria a "los proscritos de la tiranía" y, a su vez, a la deuda que tiene Chile con Argentina gracias a San Martín (Cabrera, 1902a: 10).

Para Cabrera este vínculo se fue fortaleciendo progresivamente y llevó a que se intentarán resolver los conflictos desde lo diplomático y lo pacífico. Esto llevó a que se evitaran los conflictos bélicos entre Chile y Argentina en 1895. Consecuentemente, ambos países se convirtieron en "ejemplos de fraternidad cristiana" (Cabrera, 1902a: 07) Esta ejemplificación de los estados debe ser visto como ejemplo para la sociedad. El ciudadano debe ser más fraterno y unido. A su vez, el deber ser de la nación está representado en este pacto ya que la nación prioriza la fraternidad y la unión, antes que la división y el desorden.

\section{Concluye así Cabrera:}

"La victoria del buen sentido y del honor, o más bien el triunfo de la fraternidad cristiana, en los tratados de paz, que Chile y Argentina, las dos Repúblicas hermanas acaban de signar, y con que una y otra, sin cruzamiento de espadas ni menoscabos de gloria, han resuelto finalmente una enojosa contienda" (Cabrera, 1902a: 8).

Aquí realiza una relación entre el enunciado de la fraternidad y la paz, ya que para él no pueden ser separados por su "correlación íntima y sagrada".

También cuando habla de la fraternidad elogiará al papa León XIII, a quien le profesaba mucha admiración y que ilumina este acto de paz con una efusión paternal a Argentina y Chile.

\subsection{Concepto de "Paz"}

Para desarrollar este concepto, Cabrera comenzará criticando la guerra. Para ello se remitirá al contexto mundial actual:

"Y descendiendo a los tiempos modernos, a la época contemporánea quién habrá podido imaginarse que el siglo 
XIX, el siglo de los grandes tratados, de las formidables alianzas y de las imponentes asambleas de la paz: el siglo de los acercamientos y aún de los abrazos continentales producidos por el vapor y el fluido eléctrico: el siglo de las conquistas de la unidad, (...) fue, por el contrario, cuando no teatro de las más asoladoras contiendas (...) que se apellida Paz Armada" (Cabrera, 1902a: 5-6).

Por un lado, reivindica los progresos tecnológicos y energéticos y las consecuentes ventajas de la Segunda Revolución Industrial, destacando cómo el telégrafo y otros avances estaban promoviendo la "unidad", término que reitera en varias ocasiones a lo largo del sermón. Por otro lado, critica la carrera armamentista en Europa y el fracaso de los tratados de paz como, por ejemplo, el del zar Nicolás II. Esta mención de los conflictos internacionales tiene como fin la comparación con lo que él está reivindicando en el discurso: la Paz lograda entre Chile y Argentina.

Siguiendo el sermón, considera que se dio un momento en la historia en el que comenzaron estos períodos de guerra y que sólo las ciencias sagradas fueron capaces de señalar esto: "la hora nefasta, en que un estallido formidable de soberbia, de ambición y de envidia, (...) arruinó la edad de oro, celebrada por Virgilio, y produjo en la economía divina de las sociedades humanas, perturbaciones profundas (...) esta es la clave que la Teología Católica nos presenta" (Cabrera, 1902a: 7). De esta manera, para Cabrera la única que tiene una real consciencia de lo que es bueno para las sociedades es la Iglesia y la religión. Por lo tanto, es ella quien debe guiarnos por el buen camino.

A su vez, Cabrera aclara que se debe disipar una concepción de paz platónica, proponía una paz más realista, y pensar desde los hechos terrenales y humanos. El logro de la Paz de Chile y Argentina es un ejemplo de una Paz no "de ensueño" como él la llama, sino pensada en el presente y en la "realidad auspiciosa" (Cabrera, 1902a: 8).

Además de lo planteado, para pensar la paz Cabrera va a realizar, luego del recorrido trazado sobre la amistad histórica entre ambos países, un análisis más detenido sobre la cercanía de una guerra entre Chile y Argentina en 1895. Para ello desarrolla el proceso de compra de arsenales y cómo se iban preparando para la guerra ambos países desde lo armamentístico hasta la sociedad. Aquí se hace visible la preocupación del presbítero por este conflicto en su momento. Plantea la necesidad de pensar con prudencia y moderación; cita la obra de Juan Bautista Alberdi "Las Bases y Puntos de Partida para la Organización Política de la República Argentina” para que se pensara en la paz, no por el heroísmo sino por la prosperidad. En este conflicto que parecía inminente Cabrera relata de forma retórica su resolución:

"Véase, en efecto, esfumarse por otra las nieves y los hielos, una sombra. Viste de escarlata. Es Caín?... Es Atila?... Es Aníbal?... No, señores!... Es un apóstol. Es el Jefe de la Iglesia de Chile, que cual otro Pedro el Ermitaño, viene predicando una cruzada, la Cruzada de la concordia y de la paz (...) Sí; 
es el carro de la fraternidad cristiana, que vuela a través de las inmensidades de la Pampa, arrastrado triunfalmente por los corceles alados de la civilización. Y el apóstol penetra por las avenidas de la gran capital (...) ¡Pax vobis!... exclama, bendiciendo a las muchedumbres de ciudadanos y guerreros que le contemplan sorprendidos. ¡Pax vobis!... fueron las palabras con que inauguró Jesucristo en la tierra su obra de Redención" (Cabrera, 1902a: 12-13).

Esta cita plantea el concepto de cruzada civilizatoria por la paz. Lo interesante de este concepto es que Cabrera lo repetirá luego en otros sermones en donde lo que legitima es el avance hacia los pueblos siempre en pos de la cristianización de los mismos $^{6}$. Los usos de la historia colonial para reivindicar la tarea evangelizadora de la Iglesia en el presente serán un uso recurrente de los sermones y, posteriormente, los estudios históricos de Cabrera. En este discurso, particularmente, él no se detiene en la historia colonial -recordemos que estamos ante un joven Cabrera-, pero ya empiezan a aparecer ciertas características de su pensamiento. Esto se verá en obras como La Conquista Espiritual del Desierto (Cabrera, 1934) en la que se detiene a investigar archivos "de primera agua" sobre los pueblos indígenas residentes en las pampas del sur de Buenos Aires y el proceso de Conquista; o Córdoba del Tucumán prehispánica y protohistórica, en la que se destaca la labor de evangelización de los españoles y preservación de las lenguas indígenas (Cabrera, 1931).

Por último, para él "la Paz es la suprema bendición del Cielo sobre los pueblos que guardan inviolablemente las leyes de la fraternidad y el arca santa de sus tradiciones y recuerdos" (Cabrera, 1902a: 10). A la misma la enlaza con la fraternidad y considera que parte de su esencia está basada en las tradiciones, en la historia de los pueblos que le dan legitimidad. Este pensamiento va a ser muy característico de Cabrera y, más adelante, dejará su impronta en sus estudios históricos. Para él, la tradición irá marcando los orígenes de la nación argentina e irá determinando ciertas características de los argentinos. Esa tradición que para este sacerdote-historiador se inicia en el período colonial con el proceso de evangelización marca a las sociedades y les brinda una identidad. La colonia será la madre patria. El triunfo de los Pactos de Mayo se debe al cuidado de esta tradición y de la fraternidad. La paz va a estar asociada al respeto de las tradiciones y costumbres de los pueblos. El cumplimiento y respeto de las tradiciones chilenas y argentinas se demuestra en estos tratados de paz firmados en 1902, que se están celebrando.

Cabrera venía desempeñándose previamente como orador sagrado en distintos eventos de la jerarquía eclesiástica. La realización de este discurso lo consagrará como tal. Es más, el hecho de su elección para desempeñarse como orador en semejante evento, atestigua ya la posición que el joven tenía en la Iglesia cordobesa y nacional. En el periódico Los Principios será reiteradamente felicitado por su discurso y el hecho que

${ }_{6}^{6}$ Ejemplo de esto es el folleto que elabora en 1932 sobre su oposición a la aceptación legal del Divorcio, el mismo título nos adelanta estas ideas: "El divorcio es un retroceso a la barbarie" (Cabrera, 1932). 
publiquen fragmentos del mismo o su totalidad en los distintos periódicos del interior y de Buenos Aires es un reflejo de la relevancia que el mismo tuvo ${ }^{7}$.

Sin embargo, según las fuentes, el Te Deum realizado por Cabrera en el Cristo Redentor dos años más tarde, no tuvo la grandeza de este primero y posteriormente se fue alejando de la cátedra sagrada.

\section{Sermón del 25 de Mayo}

El manuscrito que ha llegado a nuestras manos no está fechado. Tampoco encontramos que el mismo haya sido publicado en algún periódico o por alguna imprenta. Volviendo a las listas bio-bibliográficas confeccionadas por Guillermo Furlong, él hace alusión a cuatro sermones titulados "25 de mayo" (Furlong Cardiff, 1945: 199): uno de 10 folios, otro de 16 páginas, otro de 20 páginas y un último de 7 páginas. Hemos tenido acceso sólo al que analizamos que tiene 11 folios, por lo que suponemos que es el catalogado por Furlong, con una extensión de 10 folios de fecha de 1902.

La lectura de este sermón podría hacernos pensar que está datado en esa fecha aproximada. Este manuscrito tiene múltiples tachados y sobreescritos que denotan su calidad de borrador. Sin embargo, la letra de Cabrera es relativamente clara, a diferencia de la letra manuscrita de sus últimos años de vida, que es muy difícil de leer.

El discurso está dividido en tres partes que se concentran en un tema particular. Nos detendremos en el análisis de cada una de ellas. Cabrera siguió la estructura formal clásica de los sermones. Silvano Benito Moya desarrolla las partes del sermón en la que vemos claras coincidencias (2008: 84). Seguiremos esta estructura para analizar este sermón. Cabrera inicia sus sermones con un tema, es decir, citas bíblicas en lenguas latinas la cual marcaba el asunto del sermón. A continuación se encontraba el exordio proseguido por las partes argumentativas. Según Benito Moya lo más común era que las argumentaciones se dividieran en dos partes aunque algunos sermones eran tripartitos. A este discurso Cabrera lo dividió en tres, aunque otros sermones eran divididos por él en dos. Por último, la conclusión realizaba alguna reafirmación de lo ante dicho y algún ruego o petición a la Divinidad. En esto, el discurso analizado no estaba exento. Si bien explicitamos el caso de este discurso, debe aclararse que que, en general, Cabrera se atuvo a las estructuras sermonísticas tradicionales.

\subsection{Primera Parte: el pasado colonial: la Madre Patria}

La primera parte hace una rememoración, como ya había hecho en el Te Deum, de la historia del pasado colonial, donde reivindica la obra de los españoles y la Iglesia durante la colonia. La razón por la que considera necesario recordarle al público este pasado es su deber ser como sacerdote. Para Cabrera el sacerdote no debe "adular y profanar", sino encauzar los corazones para lograr el himno de paz, la unión y la fraternidad de la nación. De esta manera, su rol como sacerdote reside en decir verdades de manera humilde pero certera:

\footnotetext{
7 Por ejemplo en Los Principios, Córdoba, 30 de mayo de 1902.
} 
"Señores: Soi (sic) argentino como vosotros y amante por ende de mi patria como el que más! (...) líbreme el cielo de prostituir en la ebriedad del entusiasmo el carácter de mi augusto ministerio con los acentos viles de la rastrera adulación! Líbreme el cielo de profanar este sagrado recinto, de menoscabar el honor de esta tribuna santa con los ecos destemplados de los odios y los rencores" (Cabrera, 1902b: 1).

El sacerdote debe poder expresar las opiniones del acontecer cotidiano sin manifestar posicionamientos políticos. Se intentaba informar y formar al auditorio para que actuara en consecuencia, convenciéndolo de lo bueno o lo malo de las decisiones que se sucedían, apoyando la organización de un Estado independiente a partir de la compleja Nación existente (Martínez de Sánchez, 2010: 9). La dificultad de esta tarea residía en que debía ser hecha de tal manera que no pareciera un acto político.

Luego de esto comienza el análisis de la historia colonial. La premisa que plantea es que la causa de la independencia se consolida gracias a la colonia. Con esto intenta frenar las críticas y deslegitimaciones que se le han hecho al período, ya que considera que ha sido "iluminador". No niega injusticias y "luchas sangrientas" pero, en realidad, el buen ciudadano no debe recordar los odios y las venganzas sino "los esplendores de la magnanimidad y belleza que distinguieron muchas veces a aquellos siglos memorables" (Cabrera, 1902b: 2). En este punto es crucial recordar que el momento histórico en que escribe este sermón tiene como primer plano las luchas entre católicos y liberales de fines del siglo XIX. Esta premisa no es inocente y el uso del pasado colonial para reivindicar una de estas facciones es evidente. Por cuestiones de extensión no me detengo mayormente en este análisis (Reyna Berrotarán, 2011).

Aquí es crucial hacer una aclaración respecto de cómo concebía Cabrera el período colonial. En tanto la empresa colonizadora de los españoles fue acompañada de la evangelización, sendas cuestiones eran indisolubles para hablar del período colonial. Esto lo adelantábamos en el análisis de la pieza oratoria anterior; el período colonial será un ejemplo del pasado respecto a un presente que necesita una "re-evangelización".

Volviendo al discurso, expone ante el público que el tiempo previo a la colonización española fue un "negro manto de tinieblas" en el que los indígenas se encontraban: "sentados en las sombras de la ignorancia, hambrientos estaban de la luz, de los esplendores de la voluntad divina”. De esta manera, la llegada de la evangelización "ilumina" a estos pueblos, y los civiliza. La gesta colonizadora permitió la formación de la Madre Patria. Para todo el análisis de esta parte del sermón, Cabrera juega con conceptos de oposición como de la luz y la sombra, la civilización y la barbarie -común en los círculos intelectuales de la época-. Pero aquí hay que hacer una salvedad, porque para este presbítero, la civilización no es el avance español sino la evangelización de los pueblos. La civilización es el "Dios iluminador" que aparece ante las sombras de las creencias de los diversos grupos indígenas. Si bien esto último no está tan marcado en 
esta pieza de oratoria, lo va a marcar en algunas obras o discursos históricos (Cabrera, 1934). Este juego de palabras se puede ver en la cita a continuación:

"Prez y gloria eterna a la que rompió el negro manto de las tinieblas e iluminó nuestra frente con los destellos de la civilización cristiana! Prez y gloria inmarcesible a esos intrépidos descubridores, a esos apóstoles generosos que, surcando anchurosos mares arribaron a nuestras playas, escalaron nuestras nevadas montañas, atravesaron nuestros ríos, recorrieron nuestros desiertos y penetraron nuestros bosques para iniciarnos en la luz de la verdad y derramar los esplendores de la fe" (Cabrera, 1902b: 3).

A su vez, este párrafo nos clarifica la visión de la evangelización. Según el sacerdote-historiador, estos "apóstoles generosos" son héroes, "nuestros héroes", ya que gracias a la colonización que ellos realizaron se formó y consolidó la Madre Patria.

El sermón prosigue con la idea de la presencia de la providencia divina en la Historia Argentina. Cabrera lo manifiesta: "gratitud con el Dios de las naciones". A lo largo del discurso, y también en otras obras y sermones de Cabrera, subyace el planteo de la presencia de Dios detrás de todos los sucesos de la historia. Esta concepción de la historia se vincula con su lugar en la Iglesia y con el importante rol de la cátedra sagrada como espacio de difusión de un mensaje evangelizador.

Luego de este análisis y cerrando esta primera parte, retorna a la efemérides por la que realiza el discurso, y recuerda la deuda que se tiene con los próceres de la independencia y la madre patria y la luchas de la historia colonial que posibilitaron el surgimiento de estos héroes y de esta nación.

\subsection{Segunda parte: el deber ser ciudadano: autoridad y libertad}

En esta parte se concentra en explicar el orden de las cosas y del mundo y cómo debe ser el ciudadano. Este "deber ser" se encontrará muy vinculado a la sumisión ante la autoridad y la cautela en el exceso de la libertad. Cabrera indica como principio ordenador del mundo lo siguiente:

"Desde que la humanidad salió de manos del Creador, ha tenido que reconocer este principio sagrado. El orden domestico se conserva por la autoridad del padre de familia: el orden social por la autoridad del magistrado, el orden espiritual por la autoridad del sacerdote y el orden universal de cuanto existe, por la autoridad de Dios, que es la autoridad por exelencia, norma, principios, fuente de todo poder y a quien obedecen los cielos y la tierra" (Cabrera, 1902b: 5) ${ }^{8}$.

\footnotetext{
8 Subrayado del manuscrito original.
} 
Estos son los principios jerárquicos en que se organiza el poder y el mundo. Estos deben ser cuidados y respetados por el ciudadano. Si este no respeta este orden, el mismo desaparece y, consecuentemente, la unidad se vuelve imposible. Más adelante ejemplifica este desorden con la secesión de Buenos Aires en el período de 1850-1860 y el desorden en que se sumió el país al dejar la soberanía absoluta en manos de los hombres (Cabrera, 1902b: 4).

Consecuentemente con lo anterior, el ciudadano debe respetar el rol que le sea designado y sumirse a la autoridad que le corresponda. Esa es la fórmula para ser un buen ciudadano, pues la autoridad va a estar muy vinculada a la de libertad ya que, según Cabrera "la autoridad no puede ser causa de alarma para la libertad: es más bien su garantía. No es su ruina, es la fuente de donde emana. No es su rival, es su buena y cariñosa madre. La libertad es a la autoridad lo que la filiación a la paternidad" (Cabrera, 1902b: 5-6)

De esta manera, si el ciudadano se deja librado a "las pasiones" o al no cumplimiento de la autoridad, se convierte en esclavo de la libertad, desune y desordena la sociedad; esto la lleva a la crisis. Siendo que en la lógica de monseñor, el buen ciudadano vela por la unión social y la fraternidad -reaparecen los conceptos del Te Deum analizado previamente-. Es, entonces, cuando será libre de elegir, respetar y venerar a la autoridad: "somos libres acatando la ley". Para el autor, todo esto traería inevitablemente como consecuencia el progreso social.

Ahora bien, esta libertad que el ciudadano tiene ha sido dada por Dios para luchar contra las pasiones. Para Cabrera, "solo si obedecemos a Dios seremos libres". Nuevamente aparece esta visión de designio divino en las decisiones y en la obediencia a la autoridad. Lo que se está festejando este 25 de Mayo es el triunfo, a pesar de los "desvíos de la historia", del buen ciudadano y, consecuentemente, del progreso.

\subsection{Tercera Parte: El triunfo del deber ser Nación}

Como adelantábamos, para Cabrera luego de una gloriosa colonia, devino un tiempo de oscuridad, en la que,
"Quisimos radicar la soberanía absoluta en la voluntad de los hombres, cuando Dios nos tiene dicho que el solo es el Señor, y resulto un ídolo vano, y sin pensarlo nos hallamos caídos a los pies de un cruel tirano que usurpó nuestros derechos y conculcó todas nuestras libertades.
Buscamos una y otra vez la libertad en el desorden de la rebelión, cuando Dios la ha establecido en la obediencia" (Cabrera, 1902b: 8).

Si bien no nos adelanta quién sería el "tirano", a partir de otros textos escritos por él y las posteriores indagaciones, podemos pensar que se refiere a Juan Manuel de Rosas, con quien los gobiernos conservadores de ese momento se encontraban opuestos. 
Cabrera va a apoyar el gobierno de Roca, quien está en el poder en ese momento. Luego vendría el momento de la rebelión, de las pasiones exacerbadas y sólo luego llegaría el período del orden. Según este concionador, esta fue la etapa de la prueba de la patria. Para el año que el realiza este discurso, la nación se encontraría en paz y progresando.

Allí se dirige el mensaje que él quiere dar a sus oyentes; quiere manifestar que se debe cuidar y promover la paz y "que jamás la guerra fratricida nos separe (...), la sociedad será lo que nosotros seamos: si somos buenos, laboriosos, abnegados, sumisos, verdaderos patriotas, ella recogerá para formar su corona las flores que nosotros le presentemos. Acerquémonos a la religión, fuente de toda prosperidad verdadera". Es decir que el buen ciudadano y la verdadera nación no sólo deben someterse a la autoridad y cuidar la libertad, sino que deben ser religiosos, ser buenos creyentes y deben velar por la fe.

Para terminar este discurso, felicita a "la patria" por sus progresos. Habla de los progresos de los ferrocarriles, del modelo agroexportador, entre otras y cómo el paisaje se va modificando a medida que avanza el progreso: "Sí, patria mía, eres feliz! todos los pueblos de la sierra alborotados se saludan en el día de sus glorias y grandiosas conmemoraciones". En definitiva Cabrera felicita el orden que se está imponiendo en ese contexto. La organización del estado argentino a partir de 1862 va a dar lugar a un tipo de nación que considera el ejemplo de la civilización y el progreso. Y por detrás de todo este "éxito" está Dios y su mano que han ido modelando esta historia. El deber ser de una nación es una realidad palpable en este contexto que vive el autor.

El discurso se cierra de esta manera:

"Al aplaudir tanto progreso y magnificencia, al entonar el himno de la felicidad, levantad nuestro noble frente, mirad ese cielo inundado de luz y escuchad esa voz misteriosa que os diré: amad la paz y la fraternidad: servid a nuestro Dios: someteos a los preceptos de la ley: respetad a nuestros gobernantes: acabad la supresión de la autoridad. Fraternitatem".

Esta síntesis con la que cierra el sermón trae de vuelta la importancia al respeto de la autoridad, retoma los conceptos de Paz y Fraternidad del Te Deum expuestos días antes.

\section{Reflexiones finales}

A partir del análisis de la faceta de oratoria sagrada podemos realizar algunas reflexiones respecto de su rol. Monseñor Pablo Cabrera se inscribe en un contexto en el que la cátedra sagrada fue un medio de comunicación de las ideas de algunos presbíteros. La importancia que le dio a esta tarea se evidencia en la gran cantidad de sermones que fue exponiendo a lo largo de los años.

En estos sermones para Cabrera la clave residía en poder expresar su concepción del deber ser nación y del deber ser ciudadano. Esta concepción llevaba a pensar que 
para ser buen ciudadano y "patriota" se debía ser cristiano. Los valores que daba la Iglesia a sus creyentes eran la base para la construcción de una nación que progresara. En un momento de pugna entre católicos y liberales, en las que las relaciones entre la Presidencia de Julio Argentino Roca y la Santa Sede eran fluctuantes, era necesario "recristianizar la nación”. Si bien esta idea es más fuerte a partir de los años '20 y '30, esto no desmerece que estas propuestas se venían dando desde fines del siglo anterior.

De aquí que esta concepción se entremezclara con sus justificaciones a través de la historia en la que el período colonial resultaba clave para comprender el presente. El estudio del pasado colonial no se detenía en una cuestión metodológica sino que realizaba una operación de la memoria. Los usos del pasado que realizó Cabrera fueron formas de difundir la moral católica. Vincular la "gesta civilizatoria" -que para él era sinónimo de la gesta evangelizadora- de la colonia con el presente de lucha por el avance del cristianismo en Córdoba y el país, era una estrategia discursiva que el sacerdotehistoriador sostuvo toda su vida. La historia era una herramienta operacional para "recristianizar" la sociedad. Por ello, sus artículos en distintos periódicos y sus obras y sermones cívicos tenían alusiones reiteradas a la historia, cuando, muchas veces, el tema intentaba versar sobre alguna situación del presente. Los usos del pasado se pueden analizar a lo largo de toda su obra, aunque en este artículo no se pudieran profundizar.

Por lo tanto, para el deber ser de la nación el binomio fue el de la Paz y la Fraternidad, mientras que para el deber ser ciudadano fue la Autoridad y la Libertad. Ambos se respaldaban en la obra de un Dios superior que todo lo ordenaba. La sumisión a este orden era la clave para llegar a ser un buen ciudadano y una nación próspera.

Para finalizar, si bien Cabrera no se dedicó toda su vida a la oratoria sagrada, estas ideas que se marcaban en sus sermones se continuaron en sus obras históricas en las que se puede leer entrelíneas al orador sagrado de los libros. La consagración de esta etapa, como adelantábamos, fue cuando le otorgaron el título de Monseñor, por parte de la Santa Sede, el 3 de noviembre de 1908: "Este título implica el reconocimiento de su labor eclesial y sólo lo puede otorgar la Santa Sede, ya sea que el presbítero tenga un cargo o sólo como titular. El título fue otorgado en calidad de camarero de Su Santidad" (Vera Correa, 1988). A partir de este momento comienza una etapa en la que toma fuerza su trayectoria intelectual en la que publicó la mayoría de sus obras históricas y artículos periodísticos. Sin embargo, las características de su oratoria sagrada se sostuvieron a lo largo de toda su trayectoria. Esta etapa de su vida es clave para comprender toda la obra que ha legado a la posteridad. 


\section{Referencias Bibliográficas}

\section{Fuentes}

Los Principios, periódico católico, Córdoba, 30 de mayo de 1902.

La Tribuna, periódico católico, Córdoba, 23 de junio de 1928.

El Pueblo, periódico católico, Buenos Aires, 16 de julio de 1933.

Alocución de Monseñor Gustavo Franceschi. Boletín de la Academia Argentina de Letras, t IV, nº 13, enero-marzo de 1936, Buenos Aires.

Cabrera, Pablo 1902a. Discurso "Paz y Fraternidad" del Sr. Pbro. Dr. Pablo Cabrera en el Te Deum de acción de gracias, 24 de agosto de 1902, Iglesia Catedral de Buenos Aires, Tipográfica y Enc. La Industrial-Constitución.

Cabrera, Pablo 1902b. Discurso de 25 de mayo, Manuscrito inédito. Archivo del Arzobispado de Córdoba.

Cabrera, Pablo 1931. Córdoba del Tucumán prehispana y proto-histórica, Córdoba, imprenta de la Universidad Nacional de Córdoba.

Cabrera, Pablo 1934. La conquista espiritual del desierto, Córdoba, Imprenta de la Universidad.

Cabrera, Pablo 1934. Introducción a la historia eclesiástica del Tucumán: 1535 a 1590, Buenos Aires, Ed. Santa Catalina.

Instituto de Estudios Americanistas 1937. Acto inaugural y antecedentes, Córdoba, Universidad Nacional de Córdoba.

\section{Bibliografía}

Benito Moya, S. 2008. "In Principio erat verbum. La escritura y la palabra en el proceso de producción del sermón hispanoamericano". En: A. M. Martínez de Sánchez (comp.) Oralidad y Escritura. prácticas de la palabra: los sermones, Córdoba, Programa de Estudios Indianos, Centro de Estudios Avanzados, Universidad Nacional de Córdoba.

Cuadriello, J. 1995. "Atribución disputada: ¿Quién pintó a la Virgen de Guadalupe?”. En: Los discursos sobre el arte. XV Coloquio Internacional de Historia del Arte, Estudios de arte y estética 35, México, UNAM.

Di Stefano, R.; Zanatta, L. 2000. Historia de la Iglesia Argentina desde la conquista hasta fines del siglo XX, Buenos Aires, Ed. Sudamericana.

Furlong Cardiff, Guillermo 1945. Monseñor Pablo Cabrera: su personalidad, su obra, su gloria, Buenos Aires, Huarpes.

Ghio, J. M. 2007. La Iglesia católica en la política Argentina, Buenos Aires, Prometeo Libros.

Lacoste, P. 2001. "Argentina y Chile al borde de la guerra (1881-1902)". En: Anuario 1 del Centro de Estudios Históricos "Profesor Carlos S. A. Segreti", Córdoba, pp. 301-328.

Lacoste, P. 2002. "Argentina, Chile y los Pactos de Mayo (1902)". En: Revista Diplomacia, $\mathrm{n}^{\circ} 89$, Santiago de Chile. 
Berrotarán. Monseñor Pablo Cabrera, el "deber ser nacional” y el "deber ser ciudadano” en sus sermones.

López, M. V. 2010. “Instituciones, asociaciones y formaciones de la 'alta cultura' en el giro de siglo cordobés: entre universalismo y especialización”. En: A. Agüero y D. García (comps.), Culturas interiores. Córdoba en la geografía nacional e internacional de la cultura, La Plata, ediciones Al Margen.

Martínez de Sánchez, A. M. 2008. Oralidad y Escritura. prácticas de la palabra: los sermones, Córdoba, Programa de Estudios Indianos, Centro de Estudios Avanzados, Universidad Nacional de Córdoba.

Martínez de Sánchez, A. M. 2010. El valor de la palabra en sermones patrios. ¿Libertad o independencia? Córdoba, Programa de Estudios Indianos, Centro de Estudios Avanzados, Universidad Nacional de Córdoba.

Martínez Paz, E. 1936. Elogio de Mons. Pablo Cabrera. Córdoba: Junta de Historia y Numismática Americana, Filial de Córdoba.

Reyna Berrotarán, D. 2011. "La Historia como herramienta de legitimación de la Iglesia a principios del Siglo XX. El caso de Monseñor Pablo Cabrera”. En: M. Philp (comp.) Intervenciones sobre el pasado, Córdoba, Alción Editora.

Reyna Berrotarán, D. 2015. "Doctor Honoris Causa a Monseñor Pablo Cabrera: las líneas historiográficas de un homenaje”. En: Revista Coordenadas, Revista de Historia Local y Regional, Río Cuarto, Universidad Nacional de Río Cuarto.

Sánchez Gaete, M. 2008. "De Arauco a la vida eterna, un camino en el sermón”. En: A. M. Martínez de Sánchez (comp.) Oralidad y Escritura. Prácticas de la palabra: los sermones, Córdoba, Programa de Estudios Indianos, Centro de Estudios Avanzados, Universidad Nacional de Córdoba.

Valenzuela Márquez, J. 2001. Las liturgias del poder: celebraciones públicas y estrategias persuasivas en Chile colonial (1609 - 1709), Santiago de Chile, Centro de Investigaciones Diego Barros Arana.

Vera Correa, Manuel Alejo 1988. Monseñor Pablo Cabrera: homenaje a sus memorias, San Juan, Editorial Sanjuanina.

Vidal, G. 2006. "Ciudadanía y asociacionismo, los círculos obreros en la ciudad de Córdoba (1897-1912)". En: Revista de la Escuela de Historia, v.1, n. 5, Salta.

Zaragoza, V. 2008. "El sermón como fuente: una aproximación bibliográfica". En: A. M. Martínez de Sánchez (comp.) Oralidad y Escritura. Prácticas de la palabra: los sermones, Córdoba, Programa de Estudios Indianos, Centro de Estudios Avanzados, Universidad Nacional de Córdoba. 